\title{
BMJ Open Preferences for engagement in health technology assessment decision-making: a nominal group technique with members of the public
}

\author{
Sally Wortley, ${ }^{1}$ Allison Tong, ${ }^{1,2}$ Kirsten Howard ${ }^{1}$
}

To cite: Wortley S, Tong A, Howard K. Preferences for engagement in health technology assessment decision-making: a nominal group technique with members of the public. BMJ Open 2016;6:e010265. doi:10.1136/bmjopen-2015010265

- Prepublication history and additional material is available. To view please visit the journal (http://dx.doi.org/ 10.1136/bmjopen-2015010265).

Received 15 October 2015 Revised 8 December 2015 Accepted 8 January 2016

CrossMark

\begin{abstract}
${ }^{1}$ Sydney School of Public Health, The University of Sydney, Camperdown, New South Wales, Australia ${ }^{2}$ Centre for Kidney Research, The Children's Hospital at Westmead Corner Hawkesbury and Hainsworth Street, Westmead, New South Wales, Australia
\end{abstract}

Correspondence to Sally Wortley;

sally.wortley@sydney.edu.au

\section{ABSTRACT}

Objective: To identify characteristics (factors) about health technology assessment (HTA) decisions that are important to the public in determining whether public engagement should be undertaken and the reasons for these choices.

Design: Focus groups using a nominal group technique to identify and rank factors relevant to public engagement in HTA decision-making. Thematic analysis was also undertaken to describe reasons underpinning participants' choices and rankings.

Setting: Members of the Australian general public. Participants: 58 people, aged 19-71 years participated in 6 focus groups.

Results: 24 factors were identified by participants that were considered important in determining whether public engagement should be undertaken. These factors were individually ranked and grouped into 4 themes to interpret preferences for engagement. Members of the public were more likely to think public engagement was needed when trade-offs between benefits and costs were required to determine 'value', uncertainties in the evidence were present, and family members and/or carers were impacted. The role of public engagement was also seen as important if the existent system lacked transparency and did not provide a voice for patients, particularly for conditions less known in the community.

Conclusions: Members of the public considered value, impact, uncertainty, equity and transparency in determining when engagement should be undertaken. This indicates that the public's preferences on when to undertake engagement relate to both the content of the HTA itself as well as the processes in place to support HTA decision-making. By understanding these preferences, decision-makers can work towards more effective, meaningful public engagement by involving the public in issues that are important to them and/or improving the processes around decision-making.

\section{INTRODUCTION}

Health technology assessment (HTA) is a multidisciplinary process used by healthcare

\section{Strengths and limitations of this study}

- This study uses both nominal groups ranking and thematic analysis to interpret focus group data.

- Purposive sampling was undertaken to include a diverse range of people.

- Participants, however, were drawn from a metropolitan area in Australia and it may be that the views expressed in this study are not representative of those living outside such areas.

- This was a complex topic for participants to understand, and other research in this area would be helpful to explore this topic.

or policy-making bodies (to be referred to here as HTA organisations-HTAOs) to assist with decisions regarding the use, or reimbursement of, a health technology or service. Increasingly, public engagement is seen as imperative in HTA to ensure the legitimacy, relevance and fairness of this decisionmaking. ${ }^{1-3}$ Patients, consumer advocacy groups or lay citizens may be involved in this 'public' engagement process. ${ }^{4}$ Approaches to public engagement vary and range from provision of information, opinion surveys, committee representation to more deliberative methods such as consensus panels and citizens' juries ${ }^{5}$ — with most HTAOs undertaking some level of public engagement. ${ }^{6}$

Judgements are made by the particular HTAO as to who to engage, when to engage and the method of engagement. The rationale behind these decisions is often not explicit, however, it has been suggested that these judgements are influenced by a number of factors including the topic to be assessed, the culture of the HTAO, ${ }^{7}$ the stage of the HTA process at which engagement is sought, ${ }^{8}$ as well as time and resource pressures facing the particular organisation. ${ }^{9}$ It is also increasingly acknowledged that evidence regarding 
the effectiveness and/or impact of public engagement on HTA decision-making is lacking. ${ }^{10}$ As such, there are still many gaps in our knowledge as to what constitutes best practice for public engagement.

Most public engagement research has focused on the experiences of patient and consumer advocacy groups, rather than the lay citizen. ${ }^{11} 12$ Reviews of public engagement practices ${ }^{4} 8$ have shown that lay citizens are more likely than patients or consumer advocacy groups to be involved in policy and deliberation processes. The role of the citizen in these processes is often to provide a perspective on overarching methodological, social value or ethical issues. In the field of HTA, this often takes the form of a standing panel ${ }^{13}$ that provides guidance to an HTAO. By contrast, the views of patients and consumer advocacy groups are often actively solicited in order to add to the understanding of harms and benefits on a particular health technology or service. ${ }^{4}$ While lay citizens (or what we will hereafter refer to as the 'public') are not excluded from such processes, it is often unclear what role they can play in such circumstances given the input of other groups.

Certainly for some decisions it would seem that the public do wish to have input. ${ }^{1415}$ These are often where the content of the HTA is controversial, such as where access to pharmaceuticals requires large out-of-pocket expenses to an individual, the condition is severe and/ or there is a lack of treatment alternatives, but are these the only circumstances? Many of these factors are similar to the ones identified as important in determining allocation of resources within the HTA process. ${ }^{16-19}$ We speculate that this may be because the values that underpin both decision-making and engagement are similar, ${ }^{20}$ with public engagement providing a mechanism to legitimise decisions around priorities in healthcare. The factors for public engagement, however, are likely to have a different focus and may be more about assisting in situations of uncertainly and where trade-offs are needed. ${ }^{21}$ Furthermore, we anticipate that it will not only be the content of the HTA itself, but how decisions are made (ie, the process) that will influence perceptions about when public engagement is needed. ${ }^{22}$ This study aims to identify the decision characteristics (or factors) that are important to the Australian public in determining whether engagement should be undertaken in the HTA decision-making process, and the reasons underpinning these choices.

\section{METHODS}

\section{Study design and participants}

Participants were recruited by a market research company. Focus group participants were Englishspeaking lay members of the Australian public aged 18 years or older. To reflect a broad cross-section of the public as might be recruited for processes such as citizens juries, ${ }^{23}$ participants were purposively selected to include a range of sociodemographic characteristics, such as education, employment, cultural background, sex and parental status (whether or not the person is a parent, ie, has children). The market research company recruited participants to each group from their existing database to ensure a range of these characteristics. The group meetings were held at two venues and at various times during June-July 2014 to accommodate different schedules. The groups were split according to age (18$35,36-54$ and 55-74 years) to promote rapport in the focus group component as it was anticipated that preferences might vary according to age. ${ }^{24}$ We aimed to recruit a minimum of six groups as this was expected to achieve data saturation, defined as when subsequent groups do not identify new criteria or concepts relating to the study question. ${ }^{25}$ Generally, 6-8 participants per focus group is recommended to enable diverse discussion, and allows individuals and opportunity to participate in the discussion. We confirmed 10 participants per group to account for potential non-attendance.

As outlined in the ethics submission, all participants signed a written consent form prior to participating in the focus groups.

\section{Data collection}

Following initial pilot testing of the focus group guide, we conducted a series of focus groups with members of the general public. The groups were facilitated by one of the authors (SW). A researcher observer (KH) was present at all the group meetings to take field notes on the group discussions and dynamics. Each $2 \mathrm{~h}$ focus group included four parts: (1) open discussion on public engagement practices in HTA, (2) questions about factors that are important in HTA decisionmaking, (3) a broad discussion and identification of factors affecting decision-making and public engagement and (4) an individual ranking (nominal group) exercise involving the factors identified from the latter discussion $^{26}$ (see online supplementary file). To give some context and information to the participant, four recent Australian HTA decisions were presented as vignettes. ${ }^{27-30}$ We included these context vignettes as pilot testing of the focus group questions indicated that participants needed concrete examples of HTA decisions. These vignettes were not intended to be the focal point of discussions but to give participants an idea as to the content and process of Australian HTA, and to stimulate discussion. As such, the emphasis was on national HTA decision-making.

In the nominal group exercise, each member of the group was asked to suggest the factors that they considered the most important in determining whether public engagement in HTA should be undertaken, and to give a reason for this choice. These were listed on a whiteboard or flipchart. Once each group member had contributed, the facilitators discussed each factor to ensure that participants had a consistent understanding of the listed factors. ${ }^{31}$ Depending on the group, some reframing for clarity and/or amalgamation of overlapping or 
duplicative factors occurred at this stage. The notes from this clarification phase were also used later to develop the master list where some further grouping of duplicative items occurred. Following this phase, participants were asked to rank on a sheet provided, what they thought was the most important factor (ranking of ' 1 ') to the least important factor (ranking of ' 10 ') influence public engagement from the list generated by their group.

All groups were recorded and transcribed verbatim. Data collection continued until no new factors or concepts emerged. This occurred by the sixth focus group, when no new factors were identified.

\section{Data analysis}

Nominal group ranking

To calculate the nominal group ranking, scores were assigned by one of the researchers to the factors listed by a participant. The most important factor was assigned a score of 10 , the next factor a 9 , and so on; with the last factor (the 'least important') having a score of 1. Items of the groups' common list that were not included in the top 10 by an individual were given a 0 . A master list of all factors was created by combining the common lists of all six groups. Analysis of the multiple group data was undertaken comparing the frequency and proportion of participants who included a factor in the top 10. A mean priority score for each factor was also calculated, ${ }^{31}$ by adding the scores from the ranking exercise for each factor and dividing this by the maximum score possible for the factor. ${ }^{32}$ We did not compare across group stratification due to the small sample size.

\section{Thematic analysis}

A thematic analysis ${ }^{33}$ was undertaken on the qualitative data from this exercise, and the broader discussion around decision-making and public engagement prior to this exercise. This has been shown to be helpful in interpreting data between nominal groups ${ }^{31}$ and has been used by other studies to assess preferences in healthcare settings. ${ }^{32}{ }^{34}$ Using the methods of Braun, Clarke and Terry, ${ }^{30}$ one researcher (SW) read and re-read the transcripts. The preliminary analysis was discussed with coinvestigators $\mathrm{KH}$ and $\mathrm{AT}$ who were present at the focus groups, and/or had read the transcripts (investigators triangulation) to ensure that the analysis reflected the full breadth and depth of the data collection. Through a process of comparison and review of the data, themes were then inductively developed and refined in terms of definition and scope until agreement was reached.

\section{RESULTS}

\section{Patient characteristics}

Of the 60 participants recruited, 58 participants attended six focus groups. In four groups, there were 10 participants each, with the remaining two groups having nine participants due to non-attendance of 2 participants. No reason was given for non-attendance. The age of participants ranged from 19 to 71 years (mean age 46 years), 28 (48\%) were women and $36(62 \%)$ were in full-time employment. Most participants had completed tertiary study $(71 \%)$, and just over half of participants $(52 \%)$ indicated that they had children and/or dependents (table 1).

\section{Nominal group ranking}

Each group generated 9-15 factors, with 24 unique factors identified across the six groups (table 2). The only factor common across all groups was size of eligible population. The majority of factors was identified by three or more groups. Only one factor (background for assessing health technology) was not ranked by any participant as being in the top 10 most important (priority score of 0 ). It is worth noting that while table 2 gives an indication of the factors that the public consider important in determining whether public engagement should be undertaken, it does not indicate any directionality of the factor. For some factors, the size or 'level' of the factor determined whether people wanted more or less engagement (marked by $*$ in table 2 ).

On the basis of frequency, the top-ranked factor was size of the eligible population affected by the decision,

\begin{tabular}{|c|c|c|}
\hline Characteristics & $\begin{array}{l}\text { Number of } \\
\text { participants }(n)\end{array}$ & Percentage \\
\hline \multicolumn{3}{|l|}{ Gender } \\
\hline Male & 30 & 52 \\
\hline Female & 28 & 48 \\
\hline \multicolumn{3}{|l|}{ Age, years } \\
\hline $18-24$ & 6 & 10 \\
\hline 25-34 & 11 & 19 \\
\hline $35-44$ & 12 & 21 \\
\hline $45-54$ & 9 & 16 \\
\hline $55-64$ & 14 & 24 \\
\hline $65-74$ & 6 & 10 \\
\hline \multicolumn{3}{|c|}{ Cultural background identified as Australian } \\
\hline Yes & 40 & 69 \\
\hline $\mathrm{No}^{*}$ & 18 & 31 \\
\hline \multicolumn{3}{|l|}{ Employment } \\
\hline Full time & 36 & 62 \\
\hline Part-time & 13 & 22 \\
\hline $\begin{array}{l}\text { Not working/ } \\
\text { studying/retired }\end{array}$ & 9 & 16 \\
\hline \multicolumn{3}{|c|}{ Highest level of education } \\
\hline High school & 17 & 29 \\
\hline University/college & 27 & 47 \\
\hline Postgraduate & 14 & 24 \\
\hline \multicolumn{3}{|c|}{ Parental status with dependents/children } \\
\hline No & 28 & 48 \\
\hline Yes & 30 & 52 \\
\hline Total & 58 & \\
\hline
\end{tabular}


Table 2 Factors determining importance of public engagement in health technology decision-making: modified nominal group results sorted by mean priority score

\begin{tabular}{|c|c|c|c|c|c|}
\hline Participant-identified factor & $\begin{array}{l}\text { Number of } \\
\text { groups }\end{array}$ & $\begin{array}{l}\text { Number of } \\
\text { participants } \\
\text { voting on factor }\end{array}$ & $\begin{array}{l}\text { Frequency of } \\
\text { factors in top } \\
10\end{array}$ & $\begin{array}{l}\text { Proportion of } \\
\text { participants ranking } \\
\text { in top } 10(\%)\end{array}$ & $\begin{array}{l}\text { Mean } \\
\text { priority } \\
\text { score }\end{array}$ \\
\hline $\begin{array}{l}\text { 1. Effectiveness (success rate) of the } \\
\text { health technology }\end{array}$ & 4 & 38 & 35 & 92 & 6.9 \\
\hline $\begin{array}{l}\text { 2. Potential health gain from health } \\
\text { technology }\end{array}$ & 5 & 48 & 46 & 96 & 6.2 \\
\hline $\begin{array}{l}\text { 3. Quality of HTA decision-making } \\
\text { process }\end{array}$ & 3 & 30 & 27 & 90 & 6.2 \\
\hline 4. Comparative cost and benefit & 2 & 20 & 17 & 85 & 5.5 \\
\hline $\begin{array}{l}\text { 5. Size of eligible population to have } \\
\text { access }^{*}\end{array}$ & 6 & 58 & 54 & 93 & 5.2 \\
\hline $\begin{array}{l}\text { 6. Purpose of the technology (life saving, } \\
\text { relieving symptoms) }\end{array}$ & 4 & 38 & 28 & 74 & 5.0 \\
\hline 7. Changes in quality of life & 5 & 48 & 37 & 77 & 4.8 \\
\hline $\begin{array}{l}\text { 8. Reason for the condition (role of } \\
\text { lifestyle) }\end{array}$ & 1 & 9 & 5 & 56 & 4.8 \\
\hline 9. Cost to patient (out of pocket) & 4 & 38 & 29 & 76 & 4.6 \\
\hline 10. Societal impact & 3 & 30 & 25 & 83 & 4.3 \\
\hline 11. Cost to taxpayer & 4 & 38 & 32 & 84 & 4.0 \\
\hline 12. Quality of evidence & 5 & 48 & 30 & 63 & 4.0 \\
\hline 13. Type of heath condition & 1 & 9 & 6 & 67 & 3.9 \\
\hline 14. Severity of condition & 4 & 39 & 30 & 77 & 3.8 \\
\hline 15. Likelihood of side effects & 3 & 28 & 21 & 75 & 3.6 \\
\hline 16. Age of eligible population* & 5 & 49 & 36 & 73 & 3.6 \\
\hline 17. Awareness of condition in community & 1 & 10 & 8 & 80 & 3.5 \\
\hline 18. Prevention (avoiding future costs) & 3 & 28 & 17 & 61 & 3.2 \\
\hline 19. Availability of alternatives & 5 & 48 & 34 & 71 & 2.9 \\
\hline 20. Productivity gains & 2 & 20 & 14 & 70 & 2.6 \\
\hline 21. Health priority & 2 & 20 & 11 & 55 & 2.5 \\
\hline 22. Uncertainties in evidence (benefit) & 3 & 29 & 13 & 45 & 1.9 \\
\hline $\begin{array}{l}\text { 23. Characteristics of the health } \\
\text { technology }\end{array}$ & 1 & 10 & 3 & 30 & 1.0 \\
\hline $\begin{array}{l}\text { 24. Background for assessing the health } \\
\text { technology }\end{array}$ & 1 & 9 & 0 & 0 & 0.0 \\
\hline
\end{tabular}

with 54 participants ranking this in the top 10. Other factors included potential health gain, changes in quality of life, age of the eligible population, effectiveness (success rate of health technology), availability of alternatives, cost to taxpayer, quality of evidence, severity of condition and cost to patient. On the basis of the proportion of participants voting for factors and the frequency, six common factors emerged: potential health gain (46 participants ranked this in the top 10 representing $96 \%$ of participants ranking this factor in the top $10)$, size of eligible population (93\%), changes in quality of life $(77 \%)$, effectiveness of health technology $(92 \%)$, cost to the taxpayer $(84 \%)$ and severity of the condition $(77 \%)$. There were four factors that while not as frequently mentioned across the groups, were factors that particular groups regarded as important and were ranked in the top 10 by $80-90 \%$ of participants in those groups (table 2). This included awareness of condition in community which was only identified by one group, but was included in the top 10 by almost all $(80 \%)$ the participants in that group.

Similarly, when looking at the mean priority score across the factors, a slightly different set of factors emerge. While potential health gain (mean priority score 6.2), size of eligible population (mean priority score 5.2), changes in quality of life (mean priority score 4.8 ) and effectiveness (mean priority score 6.9) are still in the top-ranked factors, purpose of the technology (eg, is it life saving or for relieving symptoms), and reason for condition are also included. This indicates that for a small number of people these factors were assigned a greater value as they were particularly important. This was particularly evident for the factor pertaining to quality of the existing process (mean priority score 6.2). Issues around the quality of the HTA decision-making process were raised in three groups, with $90 \%$ of respondents $(27 / 30)$ ranking this in the top 10. Out of those $27,8(30 \%)$ voted this factor as the 
most important in determining whether public engagement should be undertaken.

As noted above, the ranking results do not give an indication of any directionality of the factor which is an important part of the interpretation. For example, in discussing size of the eligible population, some respondents felt that engagement was better placed for HTA topics that impacted on a large section of the population. Others felt that for these topics, the community did not need to be involved, but instead, engagement was needed for rare conditions or those with less of a 'voice' (less awareness in the community). The above analysis also does not take account of the interconnectedness between some of the factors, such as size of population and awareness of the condition in the community. These issues are addressed in the thematic analysis.

\section{Thematic analysis}

Four themes explaining participant's choices and rankings, and ultimately preferences regarding the extent and type of public engagement in Australian HTA decision-making were identified. These were: perceived value of the technology; impact of the HTA decision on both the individual and society; confidence in the procedural justice of the HTA decision-making process (ensuring fairness, transparency and quality of the process); and dealing with uncertainties in the HTA assessment process. These themes could be categorised more broadly as relating to either the content of the HTA itself or to the context and process of decisionmaking. Each theme is discussed below with illustrative quotes from participants.

\section{Perceived 'value' of the health technology}

The term value was used by participants in describing the trade-off between clinical benefits (and potential harms) and the costs (individual and society) of the health technology, and was often framed in terms of the evidence on a health technology. Some participants thought public engagement would be more appropriate in decisions where the size of the potential health gain was small and/or had a positive effect on quality of life including an individual's ability to work. 'Public', in these circumstances, was interpreted as patients providing detail of the benefits of treatment. However, this perspective was broadened when factors were discussed in the context of the disease, particularly the size of the population and the purpose, as well as the relative cost.

[When]. it's not very big effect, and we're talking about a lot of money, I think then it's more important to have public engagement to make the decision. (age 18-35 years)

Impact of the HTA decision on both the individual and society

Participants explained their choices in relation to the effect or 'impact' of the condition-and potential decision-on an individual, the individual's family, and the community. Demographic and epidemiological characteristics of a disease, such as the severity of the disease and the size of population were raised, as well as characteristics and clinical place of the technology (purpose, availability of alternatives, quality of life). In general, participants were less inclined to think public engagement was warranted when there were alternatives available, and when the condition was neither severe nor impacting on an individual's survival.

When there is loss of life then certainly there should be more questions, more engagement from the general public. (age 18-35 years)

Participants were also more inclined to consider public engagement in decisions where a health technology had an impact on an individual's family, for example, if a health technology resulted in a decrease in carer burden or the ability to work. Large out-of-pocket expenses were also viewed as a potential trigger for public engagement given such costs could have an impact on an individual's disposable income and, therefore, quality of life. Public engagement was also considered more valuable in situations where public reimbursement would have a substantial financial impact on the government and taxpayers. Conversely when costs to patients and government were small, some felt public engagement was less warranted.

When it's sort of such small bickies in terms of the overall costs...maybe stop wasting time even talking about that one and focus on something else. (age 55-74 years).

\section{Confidence in procedural justice of the HTA decision-making process \\ Ensuring fairness in the system}

A number of participants expressed that public engagement should be used to make sure there is a fair chance for all. This encompassed issues, such as awareness of the condition of the community, age, social responsibility or reason for the condition.

A common sentiment across the groups was that only those with a personal 'stake' in the technology would be interested in the decision-making process, and as such conditions that did not have a high profile in the community, and where patients' views may be difficult to obtain, could potentially be disadvantaged. In such circumstances, participants indicated a willingness to be involved.

I would become involved with those where there are not many affected but need a voice. (age 55-74 years)

\section{Transparency of the process}

Some participants were of the opinion that the public should be entitled to have a say in decisions involving distribution of taxpayers' money. 
We're taxpayers, so I think that we assume that we should be informed about where out taxpayer dollars go. (age group 36-54 years)

However, others felt that additional public engagement was not needed if there was already a fair and transparent system in place.

Well the process has to be transparent, we have to know what's going on, and maybe we're finding out for the first time there is a process. So what about the rest of the community, they would have no knowledge of this so how can they have a representative, or how can they actively and aggressively debate the issues. (age 55-74 years)

If I had confidence in the system then I'd happily sit back and go well you know I'm not going to agree with every decision but competent people have been discussing the issues the way they should. (age 55-74 years)

This also extended to the quality of the public representatives. Some participants expressed that additional public engagement would not be necessary if the public representatives in the HTA process were vocal, connected to the community that took into account patients' views and had the same level of influences as professionals within the decision-making process.

It's probably more about the quality of the representative. (age 36-54 years)

\section{Dealing with uncertainties in the assessment process}

Public engagement was deemed more important if the existing evidence was weak, conflicting or where there were uncertainties in the evidence. For example, inconsistencies around the direction of effect, or only shortterm follow-up. Other participants noted that when evidence was of good quality then public engagement may not be necessary.

I'm happy to come back in six months' time when you've got more evidence, and we might approve your drug. (age $36-54$ years)

When there is better quality evidence I will be less inclined for the need to have public engagement, because you can say "We have this evidence, we don't need to ask you, it's kind of obvious, let's do it". (age 1835 years)

Alternatively, others felt that comments from the public might serve as another form of evidence to identify those issues that really matter to patients, such as changes in quality of life.

\section{DISCUSSION}

Our study shows that there are multiple factors that are important to the Australian public in determining whether public engagement should be undertaken in HTA decision-making. Our study also shows that these factors are not solely about the content of the HTA but also about the HTA decision-making process. Participants indicated that they thought public engagement was important in situations where there were tradeoffs between effectiveness and costs, and where such decisions had an impact on individuals and their quality of life. Public engagement was also considered to be more important when the existing decision-making processes did not already take into account the views of those impacted.

Few empirical papers have been published in the HTA field on this topic. ${ }^{35}{ }^{36}$ Often studies address factors in isolation $^{2} 37$ without acknowledging the interaction between the factors. One of the strengths of this study is the linkage between quantitative rankings and the exploration of participant's reasons for ranking of factors. Perhaps related to this work is the field of priority setting in HTA, which has grown substantially in recent years. ${ }^{38}$ Most of the reported findings in this field have been in relation to 'content' values. This encompasses issues around clinical effectiveness, cost effectiveness and social value judgements around equity such as age of population and severity of disease. ${ }^{22}$ For example, in a recent study ${ }^{39}$ using a citizens jury to develop a set of criteria to guide priority-setting, three key criteria were identified; potential to benefit a number of people, potential to extend life with quality, and potential to improve quality of life. A recent Australian study undertaken to assess public preferences for funding new health technologies also found that individuals preferred technologies that benefited large numbers of people, as well as providing value for money. ${ }^{40}$ Similar results were also found in a New Zealand review conducted to assess the factors that the public wanted considered in funding health technologies. ${ }^{41}$ The final report listed four dimensions (need, health benefits, costs and savings and suitability), as well as three levels of impact (to the patient/family, society and health system).

While the results from the nominal group ranking and thematic analysis echo some of these findings, they also highlight that engagement is needed in situations such as where 'value' needs to be determined, and this 'value' needs to be determined by the public, and take into account both the benefits of a technology and the potential impact of the health technology on the individual and society. Uncertainty also appears to be a driver for the public to want to be engaged in HTA decisionmaking. Other authors have noted that as the demand for new innovative technologies increases, discussing uncertainty will need to become a fundamental part of any transparent and accountable healthcare system, ${ }^{42}$ as will issues around affordability. The thematic analysis also highlighted the impact of process in influencing preferences around engagement. For decision-makers and policy-makers this is important as it indicates that by building a system that the public trusts to be transparent and fair, that additional public engagement may not be needed. 
Further methodological exploration of the trade-offs is needed to help identify those values that are important to decision-making, and whether these trade-offs and values differ between different countries' health systems. ${ }^{22}$ This study is part of a larger mixed-methods study on public engagement, and HTA decisionmaking ${ }^{26}$ that aims to determine quantitatively, using discrete choice methodology, which factors influence the public's preferences on when and how public engagement should be undertaken for HTA decisions. The factors identified in the focus/nominal groups will be used to construct a DCE questionnaire where individuals will need to consider multiple factors. Additional items around 'how' the public is engaged in HTA decisionmaking will also be included in the DCE questionnaire. This will allow us to ascertain if the public considers that different public engagement approaches are needed depending on the particular content and process values underpinning a HTA decision. Despite a significant body of literature of public engagement, little empirical and evaluative data exists for decision-makers to draw on in order to make such choices around engagement approach. Public engagement is a resource-intensive exercise, ${ }^{43}$ and it would be good to have evidence that some of the approaches being proposed in the HTA field $^{44}$ have the support of the public.

\section{Limitations}

This was a complex topic to cover with participants unfamiliar with the HTA decision-making area. Pilot testing of the questions with a convenience sample indicated that participants needed a significant amount of guidance to understand the topic. While the focus group questions were centred on public engagement, they were situated in the context of HTA decisionmaking. For this reason, the criteria for whether the public should be engaged may reflect some of the criteria for decision-making. There had also been considerable media attention to health system changes at the time the focus group meetings were conducted, which may have led to an overemphasis on 'process' issues. Further empirical work using other approaches, such as interviews, might offer additional understandings in this area, and could be used as a comparison to our results. The population, though purposively sampled to reflect a diversity of views, did not include people from rural or remote areas, non-English speakers, and thus, it is uncertain if the findings are transferable to these populations.

\section{CONCLUSIONS}

Public preferences for when engagement should be undertaken involves consideration of factors relating to both the perceived value of the health technology and uncertainties in the HTA evidence assessment process. This is in addition to the impact of the HTA decision on both the individual and society and the public's confidence in procedural justice of the existing HTA processes. Research acknowledging the complexity of HTA decision-making and the interactions between factors is needed in order to better determine the drivers influencing the public preferences for the extent, or type of public engagement. In determining this, healthcare agencies and decision-makers can better tailor public engagement methods to optimise input from the public to where it matters most.

Contributors SW drafted the manuscript and undertook the main component of the data analysis. $\mathrm{KH}$ and $\mathrm{AT}$ reviewed and edited the paper, and $\mathrm{KH}$ formally supervised the focus group process and provided input throughout the stages. All authors read and approved the final manuscript.

Funding A research scholarship was awarded to SW from ARCS Pty Ltd to help with the conduct of this study. SW is also in receipt of an Australian Postgraduate Award.

Competing interests None declared.

Ethics approval The University of Sydney Ethics Committee approved this project (Project No: 2014/053).

Provenance and peer review Not commissioned; externally peer reviewed.

Data sharing statement No additional data are available.

Open Access This is an Open Access article distributed in accordance with the Creative Commons Attribution Non Commercial (CC BY-NC 4.0) license, which permits others to distribute, remix, adapt, build upon this work noncommercially, and license their derivative works on different terms, provided the original work is properly cited and the use is non-commercial. See: http:// creativecommons.org/licenses/by-nc/4.0/

\section{REFERENCES}

1. Littlejohns $P$, Weale A, Chalkidou K, et al. Social values and health policy: a new international research programme. J Health Organ Manag 2012;26:285-92.

2. Facey K, Boivin A, Gracia J, et al. Patients' perspectives in health technology assessment: a route to robust evidence and fair deliberation. Int J Technol Assess Health Care 2010;26:334-40.

3. Nilsen E, Myrhaug HT, Johansen M, et al. Methods of consumer involvement in developing healthcare policy and research, clinical practice guidelines and patient information material. Cochrane Database Syst Rev 2006;(3):CD004563.

4. Degeling C, Carter SM, Rychetnik L. Which public and why deliberate? A scoping review of public deliberation in public health and health policy research. Social Sci Med 2015;131:114-21.

5. Rowe G, Frewer LJ. A typology of public engagement mechanisms. Sci Technol Hum Values 2005;30:251-90.

6. Whitty JA. An international survey of the public engagement practices of health technology assessment organizations. Value Health 2013;16:155-63.

7. Gauvin FP, Abelson J, Giacomini M, et al. It all depends: conceptualizing public involvement in the context of health technology assessment agencies. Soc Sci Med 2010;70:1518-26.

8. Menon D, Stafinski T. Role of patient and public participation in health technology assessment and coverage decisions. Expert Rev Pharmacoecon Outcomes Res 2011;11:75-89.

9. OHTAC Public Engagement Subcommittee. Public engagement for health technology assessment at health quality Ontario-final report from the Ontario health technology advisory committee public engagement subcommittee. Toronto: Queen's Printer for Ontario, 2015.

10. Gauvin FP, Abelson J, Lavis JN. Strengthening public and patient engagement in health technology asessment in Ontario. Hamilton, Canada: McMaster Heatlh Forum, 2014.

11. Brett J, Staniszewska S, Mockford C, , et al. Mapping the impact of patient and public involvement on health and social care research: a systematic review. Health Expect 2014;17:637-50.

12. Daykin N, Evans D, Petsoulas C, et al. Evaluating the impact of patient and public involvement initiatives on UK health services: a systematic review. Evid Policy 2007;3:47-65.

13. Whitty JA, Littlejohns P. Social values and health priority setting in Australia: an analysis applied to the context of health technology assessment. Health Policy 2015;119:127-36. 
14. Parliament of Australia. Availability of new, innovative and specialist cancer drugs in Australia. 2015. http://www.aph.gov.au/ Parliamentary_Business/Committees/Senate/Community_Affairs/ Cancer Drugs

15. Autti-Rämö I, Mäkelä M. Screening for fetal abnormalities: from a health technology assessment report to a national statute. Int $J$ Technol Assess Health Care 2007;23:436-42.

16. Guindo LA, Wagner M, Baltussen R, et al. From efficacy to equity: literature review of decision criteria for resource allocation and healthcare decisionmaking. Cost Eff Resour Alloc 2012;10:9.

17. Husereau D, Boucher M, Noorani $H$. Priority setting for health technology assessment at CADTH. Int J Technol Assess Health Care 2010;26:341-7

18. Norheim OF, Baltussen R, Johri $M$, et al. Guidance on priority setting in health care (GPS-Health): the inclusion of equity criteria not captured by cost-effectiveness analysis. Cost Eff Resour Alloc 2014;12:18.

19. Mason H, Baker R, Donaldson C. Understanding public preferences for prioritizing health care interventions in England: does the type of health gain matter? J Health Serv Res Policy 2011;16:81-9.

20. Daniels N. Justice, health, and healthcare. Am J Bioeth 2001;1:2-16.

21. Rychetnik L, Carter SM, Abelson J, et al. Enhancing citizen engagement in cancer screening through deliberative democracy. J Natl Cancer Inst 2013;105:380-6.

22. Clark S, Weale A. Social values in health priority setting: a conceptual framework. J Health Organ Manag 2012;26:293-316.

23. Lenaghan J. Involving the public in rationing decisions. The experience of citizens juries. Health Policy 1999;49:45-61.

24. Thompson SC, Pitts JS, Schwankovsky L. Preferences for involvement in medical decision-making: situational and demographic influences. Patient Educ Couns 1993;22:133-40.

25. Onwuegbuzie AJ, Dickinson WB, Leech NL, et al. A qualitative framework for collecting and analyzing data in focus group research. Int J Qual Methods 2009;8:1-21.

26. Wortley S, Tong A, Lancsar E, et al. Public preferences for engagement in Health Technology Assessment decision-making: protocol of a mixed methods study. BMC Med Inform Decis Mak 2015;15:52.

27. Gordon L, Comans T, Scuffham PA. MRI for small bowel Crohn's disease and fistulising perianal Crohn's disease. Canberra: Commonwealth of Australia, 2013; Report No.: MSAC Application 1190.

28. Hoggan B, Cronin P, Camerson A, et al. Hyperbaric Oxygen Therapy (HBOT) for the treatment of chronic non-diabetic wounds and non-neurological soft tissue radiation injuries. Canberra: Commonwealth of Australia, 2011; Report No.: MSAC Application 1054.1.
29. PBAC. Botulinum Toxin Type A, injection. 2013. http://www pbs gov au/info/industry/listing/elements/pbac-meetings/psd/2013-07/ botulinum

30. PBAC. Ipilimumab, concentrate solution. 2012. http://www pbs gov au/info/industry/listing/elements/pbac-meetings/psd/2012-11/ ipilimumab

31. McMillan SS, Kelly F, Sav A, et al. Using the Nominal Group Technique: how to analyse across multiple groups. Health Serv Outcomes Res Methodol 2014;14:92-108.

32. Howell M, Tong A, Wong G, et al. Important outcomes for kidney transplant recipients: a nominal group and qualitative study. $A m \mathrm{~J}$ Kidney Dis 2012;60:186-96.

33. Braun V, Clarke V, Terry G. Thematic analysis. In Qual Res Clin Health Psychol 2014;95-114.

34. McMillan SS, Sav A, Kelly F, et al. Is the pharmacy profession innovative enough? Meeting the needs of Australian residents with chronic conditions and their carers using the nominal group technique. BMC Health Serv Res 2014;14:476.

35. Lopes E, Street J, Carter D, et al. Involving patients in health technology funding decisions: stakeholder perspectives on processes used in Australia. Health Expect 2015. doi:10.1111/hex.12356

36. Christiaens W, Kohn L, Léonard C, et al. Models for citizen and patient involvement in health care policy-part I: exploration of their feasibility and acceptability. Brussels: Belgian Health Care Knowledge Centre (KCE), 2012; Report No.: 195C. D/2012/10.273/105.

37. Messina J, Grainger DL. A pilot study to identify areas for further improvements in patient and public involvement in health technology assessments for medicines. Patient 2012;5:199-211.

38. Whitty JA, Lancsar E, Rixon K, et al. A systematic review of stated preference studies reporting public preferences for healthcare priority setting. Patient 2014;7:365-86.

39. Menon D, Stafinski T. Engaging the public in priority-setting for health technology assessment: findings from a citizens' jury. Health Expect 2008;11:282-93.

40. Whitty JA, Ratcliffe J, Scuffham PA. Prevention or treatment? Preferences of the Australian public for health technology assessment funding criteria. Value Health 2012;15:A306.

41. PHARMAC. Factors for consideration. 2014. http://www.pharmac. health.nz/medicines/how-medicines-are-funded/factors-forconsideration/

42. Grutters JP, van Asselt MB, Chalkidou K, et al. Healthy decisions: towards uncertainty tolerance in healthcare policy.

Pharmacoeconomics 2015;33:1-4.

43. Pizzo E, Doyle C, Matthews R, et al. Patient and public involvement: how much do we spend and what are the benefits? Health Expect 2015;18:1918-26.

44. Scuffham PA, Ratcliffe J, Kendall E, et al. Engaging the public in healthcare decision-making: quantifying preferences for healthcare through citizens juries. BMJ Open 2014;4:e005437. 